\title{
Evidence Report: The efficacy and safety of mitoxantrone (Novantrone) in the treatment of multiple sclerosis
}

Report of the Therapeutics and Technology Assessment Subcommittee of the American Academy of Neurology

James J. Marriott, MD

Janis M. Miyasaki, MD, MEd, FAAN

Gary Gronseth, MD, FAAN

Paul W. O'Connor, MD, MSc

Address correspondence and reprint requests to American Academy of Neurology, 1080 Montreal Avenue, St. Paul, MN 55116

guidelines@aan.com

\section{ABSTRACT}

Objective: The chemotherapeutic agent mitoxantrone was approved for use in multiple sclerosis (MS) in 2000. After a review of all the available evidence, the original report of the Therapeutics and Technology Assessment Subcommittee in 2003 concluded that mitoxantrone probably reduced clinical attack rates, MRI activity, and disease progression. Subsequent reports of decreased systolic function, heart failure, and leukemia prompted the US Food and Drug Administration to institute a "black box" warning in 2005. This review was undertaken to examine the available literature on the efficacy and safety of mitoxantrone use in patients with MS since the initial report.

Methods: Relevant articles were obtained through a review of the medical literature and the strength of the available evidence was graded according to the American Academy of Neurology evidence classification scheme.

Results: The accumulated Class III and IV evidence suggests an increased incidence of systolic dysfunction and therapy-related acute leukemia (TRAL) with mitoxantrone therapy. Systolic dysfunction occurs in $\sim 12 \%$ of patients with MS treated with mitoxantrone, congestive heart failure occurs in $\sim 0.4 \%$, and leukemia occurs in $-0.8 \%$. The number needed to harm is 8 for systolic dysfunction and 123 for TRAL. There is no new efficacy evidence that would change the recommendation from the previous report.

Conclusions: The risk of systolic dysfunction and leukemia in patients treated with mitoxantrone is higher than suggested at the time of the previous report, although comprehensive postmarketing surveillance data are lacking. Neurology ${ }^{\circledR} 2010 ; 74: 1463-1470$

\section{GLOSSARY}

AAN = American Academy of Neurology; $\mathbf{C H F}=$ congestive heart failure; $\mathbf{C M L}=$ chronic myeloid leukemia; FDA = Food and Drug Administration; LVEF = left ventricular ejection fraction; MIMS = Mitoxantrone in Multiple Sclerosis Group; MS = multiple sclerosis; $\mathbf{M X}=$ mitoxantrone hydrochloride; $\mathbf{N N H}=$ number needed to harm; $\mathbf{R R M S}=$ relapsing-remitting multiple sclerosis; SPMS = secondary-progressive multiple sclerosis; TRAL = therapy-related acute leukemia; TTA = Therapeutics and Technology Assessment.

Mitoxantrone hydrochloride (MX) (Novantrone ${ }^{\circledR}$, EMD Serono, Inc., Rockland, MA) is an anthracenedione initially developed as an antineoplastic agent. MX reduces lymphocyte proliferation through several mechanisms of action, including intercalation into DNA strands inducing strand breakage and inhibition of the DNA repair enzyme topoisomerase II. ${ }^{1}$ On the basis of the European Mitoxantrone in Multiple Sclerosis Group (MIMS) phase III study, the final report of which was published in 2002, ${ }^{2}$ the US
Food and Drug Administration (FDA) extended approval for the treatment of aggressive relapsing-remitting multiple sclerosis (RRMS), secondary-progressive multiple sclerosis (SPMS), and progressive-relapsing multiple sclerosis in 2000. MX is usually given IV at a dose of 12 $\mathrm{mg} / \mathrm{m}^{2}$ every 3 months until a maximum cumulative lifetime dose of $140 \mathrm{mg} / \mathrm{m}^{2}$ is reached. The Therapeutics and Technology Assessment (TTA) Subcommittee of the American Academy of Neurology (AAN) reviewed the literature on MX use in multiple 
sclerosis (MS) in 2003. ${ }^{3}$ At that time, the TTA Subcommittee reached Level B recommendations that MX was probably effective in modestly reducing clinical attack rate, MRI activity, and disease progression. (The MIMS trial was considered to represent Class II/III evidence because of incomplete blinding.) The TTA also recommended that the results of the MIMS phase III study be replicated before widespread adoption of MX as a disease-modifying agent, given the potential for treatment-related acute leukemia (TRAL) and cardiotoxicity to outweigh the clinical benefits.

In March 2005, the FDA instituted changes to the MX product labeling, including a "black box" warning about cardiotoxicity and TRAL. ${ }^{1}$ This warning was prompted by postmarketing reports of cardiotoxicity at cumulative doses $<100 \mathrm{mg} / \mathrm{m}^{2}$ as well as reports of TRAL. ${ }^{4}$ Evaluation of left ventricular ejection fraction (LVEF) prior to initiating therapy and before each subsequent dose was advised. Previously, cardiac monitoring had only been recommended prior to therapy and after each infusion once a cumulative dose of $\geq 100 \mathrm{mg} / \mathrm{m}^{2}$ had been reached. In July 2008, the FDA made the further recommendation that patients receive annual cardiac function testing after completing MX therapy because of the potential for delayed cardiotoxicity. The purpose of this update is to review the literature since the original TTA report, specifically focusing on the efficacy and safety of MX use in patients with MS.

DESCRIPTION OF THE ANALYTIC PROCESS The OVID MEDLINE and the Cochrane Controlled Trials Database were searched using the keywords mitoxantrone and multiple sclerosis. All articles published in English before July 2009 with both of these terms were retrieved (i.e., only articles pertaining to MX use in MS were considered). Recently published articles were also sought through manual searches of neurology journals and reference lists of relevant publications. Abstracts from the AAN annual meetings and the European Committee for Treatment and Research in Multiple Sclerosis Annual Conferences from 2002 to 2009 were also manually reviewed for case reports of leukemia following MX therapy.

For assessment of efficacy, only controlled clinical trials or cohort studies (Class I and Class II evidence for therapeutic articles; see appendix e-3a on the Neurology ${ }^{\circledR}$ Web site at www.neurology.org) with defined clinical or MRI endpoints published since the first TTA review were included in the analysis. For assessment of cardiotoxicity and TRAL, all published information, including case series or case reports and abstracts from poster or oral presentations, was reviewed (Class I-Class IV evidence for screening articles; see appendix e-3b).

A total of 434 articles and abstracts was retrieved through electronic searches and manual searching of abstracts and recent journal volumes. Seventeen efficacy studies published after the last TTA report were identified, including 2 Class I or II studies and 15 Class III or IV studies. Only the Class I and II studies were included in our evaluation. Eleven published Class III studies provided sufficient details to assess cardiotoxicity. TRAL was reported in 31 studies (including 4 poster/oral presentation abstracts), predominantly in small case series or individual case reports (Class III-IV).

ANALYSIS OF EVIDENCE Efficacy. No large-scale randomized controlled trial has replicated the MIMS study since the original TTA report. An MRI substudy of the MIMS trial did not show a benefit of MX on the primary endpoint (Class II evidence). ${ }^{5} \mathrm{~A}$ designed to assess the safety of MX induction before glatiramer acetate monotherapy demonstrated a greater reduction in contrast-enhancing lesions in atients treated with MX over 15 months, although no effect on relapses or Expanded Disability Status Scale progression was detected (Class I evidence). ${ }^{6}$ Therefore, the original recommendation remains Level B.

Safety. Cardiotoxicity. Cardiotoxicity (characterized by decreased LVEF and/or congestive heart failure $[\mathrm{CHF}])$ is a well-documented complication of MX use in cancer. CHF develops in 2.6\% of MX-treated patients with cancer. ${ }^{1}$ As noted in the original TTA report on MX use in $\mathrm{MS},{ }^{3}$ an early review of cardiotoxicity in MX-treated patients with MS was reported in 2002. ${ }^{7}$ This report included information from the MIMS trial, ${ }^{2}$ an open-label multicenter study from France, ${ }^{8}$ and a cohort from a single German center. ${ }^{9}$ Of the total 1,378 patients, 2 developed CHF. Follow-up LVEF assessments were performed in 779 patients; of these, 17 patients $(2.2 \%)$ developed asymptomatic LVEF $<50 \%$.

Since the initial TTA review, a series of Class III studies documented cardiotoxicity in MX-treated patients with MS (table 1), although the reported frequency, severity, and time course of cardiac complications varies markedly. Early cardiotoxicity was reported in 2 Class III studies. ${ }^{10,11}$ In the first, LVEF decreased significantly in 5 out of 28 patients $(\sim 18 \%)$ after 3 doses of MX $\left(12 \mathrm{mg} / \mathrm{m}^{2}\right.$ every 3 months). ${ }^{10}$ In the second study $(\mathrm{n}=18), 4$ patients developed asymptomatic decreased LVEF after 1-2 MX infusions at cumulative doses ranging from 17.7 to $51.4 \mathrm{mg} .{ }^{11}$ Four other patients showed evidence of isolated diastolic dysfunction. Follow-up echocardio- 


\section{Table 1 Cardiotoxicity in patients treated with mitoxantrone hydrochloride}

\begin{tabular}{|c|c|c|c|c|}
\hline Reference & Class $^{a}$ & MX protocol & Cardiac monitoring & Cardiac outcome \\
\hline 10 & IIII & $\begin{array}{l}12.5 \mathrm{mg} / \mathrm{m}^{2} \text { q } 3 \mathrm{mo}, \text { cumulative dose } \\
\leq 140 \mathrm{mg} / \mathrm{m}^{2}\end{array}$ & MUGA prior to fourth dose & $5 / 28$ patients asymptomatic $\downarrow$ LVEF \\
\hline 11 & III & $\begin{array}{l}12 \mathrm{mg} / \mathrm{m}^{2} \mathrm{q} 3 \mathrm{mo}, \text { cumulative dose } \\
\leq 100 \mathrm{mg} / \mathrm{m}^{2}\end{array}$ & TTE prior to each dose & $\begin{array}{l}4 / 18 \text { patients asymptomatic } \downarrow \text { LVEF } \\
\text { after } 1-2 \text { doses }\end{array}$ \\
\hline 12 & III & $\begin{array}{l}12 \mathrm{mg} / \mathrm{m}^{2} \mathrm{q} 1 \mathrm{mo} \times 3 \text { doses, then } \mathrm{q} \\
3 \mathrm{mo} \text {, cumulative dose } \leq 144 \mathrm{mg} / \mathrm{m}^{2}\end{array}$ & MUGA every 24 wk & $\begin{array}{l}\text { No } \downarrow \text { LVEF during treatment, late } \\
\text { CHF in } 3 / 52 \text { patients }\end{array}$ \\
\hline 13 & III & $12 \mathrm{mg} / \mathrm{m}^{2} \mathrm{q} 3 \mathrm{mo} \times 8$ doses & TTE at 24 and 48 wk & $\begin{array}{l}\downarrow \text { LVEF in } 6 / 96 \text { patients; } 3 / 96 \\
\text { w/ } \downarrow \text { LVEF }<50 \% \text { discontinued MX }\end{array}$ \\
\hline 14 & III & $12 \mathrm{mg} / \mathrm{m}^{2} \mathrm{q} 3 \mathrm{mo} \times 16$ doses & MUGA every 24 wk & $\begin{array}{l}\downarrow \text { LVEF }<40 \% \text { in } 2 / 48 \text { patients } \\
\text { at } 1 \mathrm{y}\end{array}$ \\
\hline 15 & III & $5 \mathrm{mg} / \mathrm{m}^{2} \mathrm{q} 3 \mathrm{mo}$ & $\begin{array}{l}\text { TTE or MUGA prior to fourth } \\
\text { and seventh doses }\end{array}$ & $\begin{array}{l}\downarrow \text { LVEF }<50 \% \text { in } 4 / 31 \text { patients after } \\
1 \mathrm{y}\end{array}$ \\
\hline 16 & III & $\begin{array}{l}12 \mathrm{mg} / \mathrm{m}^{2} \mathrm{q} 1 \mathrm{mo} \times 3 \text { doses, then } \mathrm{q} \\
3 \mathrm{mo} \text { until cumulative dose } 120 \\
\mathrm{mg} / \mathrm{m}^{2}\end{array}$ & $\begin{array}{l}\text { MUGA after third and sixth } \\
\text { dose }\end{array}$ & $\begin{array}{l}118 \text { patient cohort; } \downarrow \text { LVEF in } 25, \\
\text { LVEF }<50 \% \text { in } 4 \text { and an AMl in } 1 \\
\text { patient }\end{array}$ \\
\hline 17 & III & $\begin{array}{l}12 \mathrm{mg} / \mathrm{m}^{2} \mathrm{q} 1 \mathrm{mo} \times 3 \text { doses, then } \mathrm{q} \\
3 \mathrm{mo} \text { until cumulative dose } 108 \\
\mathrm{mg} / \mathrm{m}^{2}\end{array}$ & $\begin{array}{l}\text { MUGA before fourth, sixth, } \\
\text { and ninth dose and } 6 \mathrm{mo} \\
\text { after therapy }\end{array}$ & $\begin{array}{l}31 / 102 \text { patients either decrease } \\
\mathrm{LVEF} \geq 10 \% \text { or } \mathrm{LVEF}<50 \%\end{array}$ \\
\hline 18 & III & $\begin{array}{l}10 \mathrm{mg} / \mathrm{m}^{2} \mathrm{q} 3 \mathrm{mo} \times 3 \text { doses, then } \\
\text { decreasing frequency over } 5 \mathrm{y} \\
\text { (cumulative dose }<120 \mathrm{mg} \text { ) }\end{array}$ & TTE prior to each dose & $\begin{array}{l}\text { No } \downarrow \text { LVEF seen in } 73 \text { patients over } \\
5 y\end{array}$ \\
\hline 19 & III & $8 \mathrm{mg} / \mathrm{m}^{2} \mathrm{q} 2 \mathrm{mo} \times 12$ doses & & $\begin{array}{l}\text { No } \downarrow \text { LVEF seen in } 50 \text { patients over } \\
96 \text { wk of treatment }\end{array}$ \\
\hline 20 & III & $20 \mathrm{mg} / \mathrm{m}^{2} \mathrm{q} 1 \mathrm{mo} \times 6$ doses & & $\begin{array}{l}\downarrow \text { LVEF in } 3 / 100 \text { patients ( } 1 \mathrm{mo}, 1.5 \\
\text { and } 5 \text { y posttreatment) }\end{array}$ \\
\hline
\end{tabular}

Abbreviations: $\mathrm{AMI}=$ acute myocardial infarction; $\mathrm{CHF}=$ congestive heart failure; $\mathrm{LVEF}=$ left ventricular ejection fraction; MUGA = multigated radionuclide angiography; MX = mitoxantrone hydrochloride; TTE = transthoracic echocardiogram. aSee appendix e-3 for descriptions of classification of evidence.

grams showed improvement of LVEF in all patients and 2 patients subsequently resumed MX therapy without further complications.

Another Class III study of a 52-patient cohort reported late development of CHF in 3 patients between 24 and 80 months after discontinuation of MX. ${ }^{12}$ One Class III study of 96 patients who received a cumulative dose of $48 \mathrm{mg} / \mathrm{m}^{2}$ of MX over 1 year reported asymptomatic decreased LVEF in 6 patients. ${ }^{13}$ Three of these patients had LVEF $<50 \%$ at 6 months and discontinued therapy. In another Class III study of 48 patients with SPMS, 2 patients developed asymptomatic and partially reversible LVEF $<40 \%$ after 1 year $\left(48 \mathrm{mg} / \mathrm{m}^{2}\right)$ of $\mathrm{MX} .{ }^{14}$ A Class III study of 31 patients receiving $5 \mathrm{mg} / \mathrm{m}^{2}$ of MX every 3 months reported asymptomatic LVEF $<50 \%$ in 4 patients after $\geq 12$ months of treatment. ${ }^{15}$ One Class III study of 118 patients reported decreased LVEF $>10 \%$ in 25 patients, LVEF $<50 \%$ in 4 patients, and 1 myocardial infarction. ${ }^{16}$ Another Class III study of 102 patients treated with a cumulative dose of $108 \mathrm{mg} / \mathrm{m}^{2}$ reported asymptomatic decreased LVEF in 31 patients (30\%). ${ }^{17}$

Other Class III studies, however, have not demonstrated such high rates of cardiotoxicity. In one series of 73 patients, no cardiotoxicity was observed, although 2 patients receiving at least 4 doses of MX were lost to follow-up. ${ }^{18}$ Similarly, in another Class
III study of 50 prospectively assessed patients, no decrease in LVEF was seen during 2 years of therapy, although cardiac function was not assessed in 3 years of follow-up after discontinuation of MX. ${ }^{19}$ A recent Class III study of 100 patients with aggressive RRMS receiving induction MX therapy noted asymptomatic worsening LVEF in 3 patients following MX therapy. ${ }^{20}$

Consolidating these various reports provides an estimated $83 / 716(\sim 12 \%)$ rate of decreased LVEF and $3 / 716(\sim 0.4 \%)$ risk of $\mathrm{CHF}$, although the differences in MX regimens and cardiac-monitoring protocols employed in the different centers make this composite figure only a general approximation. The number needed to harm (NNH) for left ventricular dysfunction is 8 . This NNH means that for every 8 patients treated with MX, 1 patient will experience some degree of cardiotoxicity.

RENEW, a phase IV study of MX use, is ongoing. As of January 2008, CHF had developed in 2\% of the observed 509 patients, according to the latest presented data. ${ }^{21}$ Serial cardiac function results were available for 200 patients, of whom 26 (13\%) had LVEF $<50 \%$.

The iron-chelator dexrazoxane was studied in MX-treated patients with MS to evaluate a mitigating effect on MX-induced cardiotoxicity. ${ }^{22}$ The study was an open-label comparison of patients 


\begin{tabular}{|c|c|c|c|c|c|c|c|c|}
\hline Table 2 & Reported & cases of & TRAL in patients & treated & with mitoxantrone $h$ & $y_{\text {drochloride }}{ }^{a}$ & & \\
\hline Reference & $\begin{array}{l}\text { Patient age, } \\
\text { y/sex }\end{array}$ & Class $^{b}$ & Total dose & TRAL $^{\mathrm{c}}$ & $\begin{array}{l}\text { Interval between MX } \\
\text { treatment and TRAL }\end{array}$ & TRAL outcome & $\begin{array}{l}\text { Total no. } \\
\text { of patients }\end{array}$ & $\begin{array}{l}\text { TRAL } \\
\text { rate, \% }\end{array}$ \\
\hline 25 & $36 / \mathrm{M}$ & IV & $87.5 \mathrm{mg}$ & M3 & $5 y$ & Remission & 1 & NA \\
\hline \multirow[t]{2}{*}{26,36} & $30 / F$ & III & $120 \mathrm{mg}$ & M5 & $12 \mathrm{mo}$ & Death & 1378 & 0.15 \\
\hline & $24 / F$ & IV & $70 \mathrm{mg} / \mathrm{m}^{2}$ & NS & NS & NS & & \\
\hline 37 & $32 / F$ & IV & NS & NS & NS & Remission & $2^{d}$ & NA \\
\hline 38 & $56 / \mathrm{M}$ & IV & $198 \mathrm{mg}$ & M3 & $15 \mathrm{mo}$ & Remission & 1 & NA \\
\hline 29 & 4 patients & III & $31.5-215 \mathrm{mg}$ & M3 & NS & 2 relapses & 170 & 2.35 \\
\hline 39 & $34 / F$ & III & $72 \mathrm{mg} / \mathrm{m}^{2}$ & M4 & $5 \mathrm{mo}$ & Remission & 59 & 1.69 \\
\hline 23 & $28 / F$ & IV & $120 \mathrm{mg}$ & M3 & $16 \mathrm{mo}$ & Remission & 1 & NA \\
\hline 40 & $47 / F$ & III & $120 \mathrm{mg}$ & M3 & $26 \mathrm{mo}$ & Death & 255 & 0.4 \\
\hline e1 & $43 / F$ & IV & $120 \mathrm{mg}$ & M3 & $11 \mathrm{mo}$ & Remission & 1 & NA \\
\hline 32,33 & $48 / \mathrm{M}$ & III & $160 \mathrm{mg}$ & M1 & During & Remission & 304 & 0.33 \\
\hline e2 & $45 / F$ & III & $84 \mathrm{mg} ; 48 \mathrm{mg} / \mathrm{m}^{2}$ & M4eo & $28 \mathrm{mo}$ & Remission & 644 & 0.15 \\
\hline e3 & $47 / F$ & III & $15 \mathrm{mg}$ (1 dose) & M3 & $\sim 40 \mathrm{mo}$ & Death & 25 & 4 \\
\hline \multirow[t]{2}{*}{ e4 } & $21 / F$ & III & $170 \mathrm{mg}$ & M3 & & Remission & 250 & 0.8 \\
\hline & $37 / F$ & & $147.5 \mathrm{mg}$ & M3 & & Remission & & \\
\hline \multirow[t]{3}{*}{27} & $42 / \mathrm{M}$ & III & $60 \mathrm{mg} / \mathrm{m}^{2}$ & S & & Death & 134 & 2.2 \\
\hline & $58 / \mathrm{M}$ & & $96 \mathrm{mg} / \mathrm{m}^{2}$ & & & Death & & \\
\hline & $58 / \mathrm{M}$ & & $48 \mathrm{mg} / \mathrm{m}^{2}$ & & & Death & & \\
\hline e5 & 28/M & III & & & & Remission & 120 & 0.83 \\
\hline e6 & $40 / F$ & IV & & & $6 \mathrm{mo}$ & Remission & 1 & NA \\
\hline \multirow[t]{3}{*}{28} & NS & III & & NS & During & NS & 116 & 2.5 \\
\hline & NS & & & NS & $18 \mathrm{mo}$ & NS & & \\
\hline & NS & & & NS & $24 \mathrm{mo}$ & NS & & \\
\hline e7 & $58 / \mathrm{M}$ & & & NS & $4 \mathrm{mo}$ & Death & 1 & NA \\
\hline 34 & & & $96 \mathrm{mg} / \mathrm{m}^{2}$ & $\mathrm{CML}$ & $19 \mathrm{mo}$ & Remission & 1 & NA \\
\hline \multirow[t]{2}{*}{ e8 } & & & $90 \mathrm{mg} / \mathrm{m}^{2}$ & M3 & $22 \mathrm{mo}$ & Remission & 1 & NA \\
\hline & & & $96 \mathrm{mg} / \mathrm{m}^{2}$ & M3 & During therapy & Remission & 1 & NA \\
\hline \multirow[t]{4}{*}{31} & & III & $30 \mathrm{mg} / \mathrm{m}^{2}$ & M3 & $23 \mathrm{mo}$ & Death & 142 & 2.82 \\
\hline & & & $100 \mathrm{mg} / \mathrm{m}^{2}$ & M3 & $2 \mathrm{mo}$ & Remission & & \\
\hline & $59 / \mathrm{F}$ & & $70 \mathrm{mg} / \mathrm{m}^{2}$ & M3 & $11 \mathrm{mo}$ & Remission & & \\
\hline & $33 / F$ & & $60 \mathrm{mg} / \mathrm{m}^{2}$ & M3 & $1 \mathrm{mo}$ & Death & & \\
\hline \multirow[t]{4}{*}{30} & $44 / F$ & III & $96 \mathrm{mg} / \mathrm{m}^{2}$ & M3 & $25 \mathrm{mo}$ & Remission & 152 & 2.6 \\
\hline & $63 / \mathrm{M}$ & & $48 \mathrm{mg} / \mathrm{m}^{2}$ & M3 & $5 y$ & Remission & & \\
\hline & $32 / F$ & & $90 \mathrm{mg} / \mathrm{m}^{2}$ & M3 & $11 \mathrm{mo}$ & Remission & & \\
\hline & $46 / F$ & & $60 \mathrm{mg} / \mathrm{m}^{2}$ & ALL & $4 \mathrm{mo}$ & Death & & \\
\hline e9 & $35 / F$ & IV & $95 \mathrm{mg} / \mathrm{m}^{2}$ & M4 & $11 \mathrm{mo}$ & Remission & 1 & $\mathrm{~N} / \mathrm{A}$ \\
\hline e10 & $54 / F$ & IV & NS & M3 & $<1$ y (exact NS) & Remission & 1 & $N / A$ \\
\hline \multirow[t]{2}{*}{ e11 } & $53 / F$ & III & $96 \mathrm{mg} / \mathrm{m}^{2}$ & M3 & $14 \mathrm{mo}$ & Remission & 61 & 1.64 \\
\hline & $53 / \mathrm{M}$ & IV & $84 \mathrm{mg} / \mathrm{m}^{2}$ & $\mathrm{M} 2 / 4$ & $18 \mathrm{mo}$ & Death & $1^{e}$ & \\
\hline e12 & $46 / F$ & IV & $120 \mathrm{mg}$ & M2 & $\sim 10 y$ & Death & 1 & $\mathrm{~N} / \mathrm{A}$ \\
\hline \multirow[t]{2}{*}{ e13 } & NS/M & IV & $50 \mathrm{mg} / \mathrm{m}^{2}$ & M3 & NS & NS & 158 & 1.3 \\
\hline & NS/F & & $140 \mathrm{mg} / \mathrm{m}^{2}$ & NS & $2 y$ & NS & & \\
\hline
\end{tabular}




\begin{tabular}{|c|c|c|c|c|c|c|c|c|}
\hline Table 2 & Continued & & & & & & & \\
\hline Reference & $\begin{array}{l}\text { Patient age, } \\
\text { y/sex }\end{array}$ & Class $^{b}$ & Total dose & TRAL $^{\mathrm{c}}$ & $\begin{array}{l}\text { Interval between MX } \\
\text { treatment and TRAL }\end{array}$ & TRAL outcome & $\begin{array}{l}\text { Total no. } \\
\text { of patients }\end{array}$ & $\begin{array}{l}\text { TRAL } \\
\text { rate, \% }\end{array}$ \\
\hline \multirow[t]{9}{*}{ e14 } & $59 / F$ & IV & $35 \mathrm{mg}$ & M3 & NS & Remission & $14^{f}$ & N/A \\
\hline & $58 / F$ & & $70 \mathrm{mg}$ & M3 & NS & Remission & & \\
\hline & $59 / F$ & & $234 \mathrm{mg}$ & M3 & NS & Remission & & \\
\hline & $28 / M$ & & $110 \mathrm{mg}$ & M3 & NS & Recurrence & & \\
\hline & $61 / M$ & & $100 \mathrm{mg}$ & M3 & NS & Remission & & \\
\hline & $45 / M$ & & $176 \mathrm{mg}$ & M3 & NS & Remission & & \\
\hline & $45 / M$ & & $81 \mathrm{mg}$ & M3 & NS & Remission & & \\
\hline & $55 / F$ & & $64 \mathrm{mg}$ & M3 & NS & Death & & \\
\hline & $45 / F$ & & $120 \mathrm{mg}$ & M3 & NS & Remission & & \\
\hline e15 & $49 / M$ & IV & $90 \mathrm{mg}$ & M2 & NS & Remission & 1 & N/A \\
\hline \multirow[t]{2}{*}{17} & $54 / \mathrm{M}$ & IV & $72 \mathrm{mg} / \mathrm{m}^{2}$ & NS & $2 y$ & Death & 108 & 0.93 \\
\hline & $46 / F$ & & $108 \mathrm{mg} / \mathrm{m}^{2}$ & NS & $1 y$ & Death & & \\
\hline
\end{tabular}

Abbreviations: $\mathrm{ALL}=$ acute lymphoblastic leukemia; $\mathrm{CML}=$ chronic myeloid leukemia; $\mathrm{MX}=$ mitoxantrone hydrochloride; $\mathrm{NS}=$ not stated; TRAL $=$ therapy-related acute leukemia.

aThis table does not include reference 20, a cohort of 100 patients which overlaps with reference 26, and the RENEW registry (reference 21), which may also contain duplicate cases reported in references listed above.

bSee appendix e-3 for descriptions of classification of evidence.

${ }^{\mathrm{C} B y}$ French-American-British subtype unless otherwise stated, leukemia subtype not always specified.

${ }^{\mathrm{d}}$ The other patient in this reference is also discussed in references 32 and 33 .

eThe second patient in this reference is not included in the author's own cohort of 61 patients.

${ }^{\mathrm{f}}$ This article discusses 14 patients with multiple sclerosis with leukemia; not shown in the table are 2 cases not exposed to $\mathrm{MX}$ and 3 cases previously reported in other references.

treated with $(\mathrm{n}=28)$ or without $(\mathrm{n}=19)$ dexrazoxane in conjunction with MX. While a blinded assessor evaluated LVEF using multiple gated acquisition scanning, the 2 arms were recruited separately (Class III). Both patient groups experienced significant decreases in LVEF at 1 year; however, the mean percent change was lower in the dexrazoxane-treated group $(-3.8 \%$ compared with $-8.6 \% ; p<0.001)$.

Leukemia. TRAL is a recognized complication of chemotherapy. ${ }^{23}$ Most cancer patients are treated with combinations of chemotherapeutic agents, including MX, and in this population TRAL occurs in $2 \%-12 \%$ of patients, with a median time of 22 months between onset of MX therapy and TRAL. ${ }^{23,24}$

The first case report of TRAL in a patient with MS was published in 1998..$^{25}$ An early review estimated that the risk of TRAL in the MS population was $0.07 \%$ after a mean follow-up of 36 months in 1,378 patients. ${ }^{26}$ These data were based on the MIMS study ${ }^{2}$ (124 patients) and the aforementioned multicenter French ${ }^{8}$ (802 patients) and single-center German ${ }^{9}$ studies (452 patients). No TRAL was seen in the MIMS or German cohorts, but one case was seen in the French study. The authors note in an addendum to the article that a second patient in the French cohort also developed TRAL, making the corrected rate $0.25 \%$ at 3.1 years in that 802 -patient cohort, or $0.15 \%$ of the overall 1,378 patients (table 2). ${ }^{26}$

Subsequently, a number of Class III and IV case series and case reports have reported 56-57 individual cases of TRAL in MX-treated patients with MS (table 2; one patient may be duplicated in references 29 and 38). In contrast to the low incidence reported earlier, recent reports (3 as abstracts) have documented rates of TRAL between $\sim 2 \%$ and $3 \% .^{27-31}$ Additionally, in one of these cohorts, all 3 affected patients died despite adequate treatment, ${ }^{28}$ in contrast to the majority of reported cases where leukemia remission was achieved following chemotherapy and/or bone marrow transplantation (see table 2). The majority of TRAL cases in the MS population occur within a few years of MX use, the original case report being an outlier at 5 years post-therapy (see table 2).

Other case series reported lower rates of TRAL. In a Class III retrospective study of 100 consecutive French patients who received induction monthly MX boluses for 6 months ( $\max 72 \mathrm{mg} / \mathrm{m}^{2}$ ), one patient (previously reported in a larger cohort ${ }^{26}$ ) developed acute myelogenous leukemia. ${ }^{20}$ A Class III retrospective survey of 304 patients treated at a single center in France ${ }^{32}$ identified only one previously reported case of TRAL. ${ }^{33}$ The latest presented update of the United States RENEW registry reported leu- 
kemia in 3/509 patients; however, only 2 were thought to be TRAL. ${ }^{21}$

In addition, one case has recently been published of a patient developing chronic myeloid leukemia (CML) 16 months after MX therapy. ${ }^{34} \mathrm{CML}$ is not a recognized TRAL in either the cancer or MS population and it is unclear whether this malignancy resulted from the MX therapy.

Combining all of the reports listed in table 2 in which a denominator is available, the incidence of TRAL in patients with MS is 33/4,076 ( 0.81\%). The NNH for the development of TRAL is 123 . This figure is only an approximation, however, given the heterogeneity in the length of follow-up documented in the various case series. Nevertheless, this result is very similar to the findings of a recent large retrospective review from 35 Italian MS Centers that reported 21 cases of TRAL in 2,854 (0.74\%) patients treated with MX (Class III). ${ }^{35}$ These authors also demonstrated a strong doseresponse relationship, with the incidence rate ratio increasing from 1.84 at doses $\leq 60 \mathrm{mg} / \mathrm{m}^{2}$ to 2.74 at doses $\geq 82.4 \mathrm{mg} / \mathrm{m}^{2}$. (It is unclear which of these 21 cases have been previously reported in the references listed in table 2.) Fifteen curred in the 51 patients (29\%) whose outcome was reported; however, it is not known how many other patients in remission subsequently died.

Conclusions. While the Class III and IV evidence available provides conflicting estimates of both the frequency and severity of MX-related cardiotoxicity, asymptomatic decreased systolic function occurs in approximately $12 \%$ of patients treated with MX, and CHF occurs in approximately $0.4 \%$. The literature on TRAL in MX-treated patients with MS is also limited to Class III and IV evidence; however, the cumulative incidence appears to be $\sim 0.8 \%$. Both TRAL and systolic dysfunction can occur at any time after initiation of MX, including early in the treatment course.

The evidence regarding toxicity suggests the risk of systolic dysfunction associated with the use of MX in patients with MS results in an NNH of 8, and the risk of TRAL with MX therapy results in an NNH of 123. This demonstrates that the risk of both cardiotoxicity and leukemia is likely higher than earlier estimates.

CLINICAL CONTEXT Recommendations on MX use reflecting the potential for harm would require a risk-benefit analysis and are beyond the scope of an evidence-based guideline. In the absence of such an analysis, it is reasonable for clinicians to follow the recommendations outlined in the product monograph and include ejection fraction assessments before initiating treatment and administering each dose of MX and yearly after discontinuation of treatment. It is not known whether patients treated with MX with asymptomatic decreased LVEF will experience long-term sequelae. The long-term sequelae of asymptomatic cardiotoxicity is not clear. It is reasonable for clinicians to monitor patients for TRAL after MX therapy with periodic complete blood cell counts, although the optimal timing of such monitoring is not known.

Clinicians contemplating MX administration for an individual patient with MS must weigh the potential for benefit against the potential for harm given the $\sim 12 \%$ risk of systolic dysfunction and $\sim 0.8 \%$ risk of TRAL and the availability of alternative therapies with less severe toxicities (e.g., interferon- $\beta$ and glatiramer acetate) for patients with RRMS.

\section{RECOMMENDATIONS FOR FUTURE RESEARCH}

- The best evidence for MX use in MS remains the MIMS trial. The first report of the TTA in 2003 recommended that the results of this trial be replicated, and this has not occurred to date. No Class I evidence exists to support the use of MXin the MS population.

- Future trials using MX induction followed by standard disease-modifying agents should be considered. Any future trial should include a prospective, long-term safety analysis.

- While the rate of symptomatic cardiotoxicity and TRAL appears low, more reports are arising to suggest that these risks are higher than indicated by the initial evidence. It is imperative that longterm, prospective postmarketing data be compiled to better quantify the risks of MX therapy.

\section{DISCLOSURE}

Dr. Marriott has served on a scientific advisory board for Biogen Idec; has received funding for travel from EMD Serono, Inc. and Biogen Idec; and has received a speaker honorarium from Teva Pharmaceutical Industries Ltd. Dr. Miyasaki has served on a scientific advisory board for Teva Pharmaceutical Industries Ltd.; has received honoraria for educational activities not funded by industry; serves on the editorial board of Movement Disorders; has received speaker honoraria from Biovail Corporation; serves/has served as a consultant to Ortho-McNeil-Janssen Pharmaceuticals, Inc., Merz Pharmaceuticals, LLC, Schering-Plough Corp., the NIH (Independent Medical Monitor), Ontario Drug Benefits, and Common Drug Review, Canada; and receives research support from Teva Pharmaceutical Industries Ltd., Boehringer Ingelheim, Solvay Pharmaceuticals, Inc., Solstice Neurosciences, Inc., Impax Laboratories, Neurogen, Medivation, Inc., the National Parkinson Foundation, the Parkinson Society Canada, the Michael J. Fox Foundation, and the Huntington Study Group. Dr. Gronseth serves as an editorial advisory board member of Neurology Now; serves on a speakers' bureau for Boehringer Ingelheim; and receives honoraria from Boehringer Ingelheim and the American Academy of Neurology. Dr. O'Connor has served on scientific advisory boards for Novartis, Sanofi-Aventis, Bayer Schering Pharma, Genentech, Inc., and Roche; has received funding for travel from Biogen Idec, Teva Pharmaceutical Industries Ltd.; has received speaker honoraria from Biogen Idec; serves as a consultant for Biogen Idec, Bayer Schering Pharma, Daiichi Sankyo, Abbott, Genzyme Corporation, BioMS Medical, Schering-Plough Corp., Novartis, EMD Serono, Inc., Sanofi-Aventis, Teva Pharmaceutical Industries Ltd., and Genentech, Inc.; has received research support from Biogen Idec, Schering- 
Plough Corp., BioMS Medical, Genentech, Inc., Bayer Schering Pharma, Novartis, Sanofi-Aventis, Roche, and the NIH (1 U01 NS 45719-01 A1 [Site PI]); and estimates that $25 \%$ of his clinical effort is spent on evoked potentials in MS diagnosis.

\section{DISCLAIMER}

This statement is provided as an educational service of the American Academy of Neurology. It is based on an assessment of current scientific and clinical information. It is not intended to include all possible proper methods of care for a particular neurologic problem or all legitimate criteria for choosing to use a specific procedure. Neither is it intended to exclude any reasonable alternative methodologies. The AAN recognizes that specific patient care decisions are the prerogative of the patient and the physician caring for the patient, based on all of the circumstances involved. The clinical context section is made available in order to place the evidence-based guideline(s) into perspective with current practice habits and challenges. No formal practice recommendations should be inferred.

\section{CONFLICT OF INTEREST}

The American Academy of Neurology is committed to producing independent, critical and truthful clinical practice guidelines (CPGs). Significant efforts are made to minimize the potential for conflicts of interests to influence the recommendation of this CPG. To the extent possible, the AAN keeps separate those who have a financial stake in the success or failure of the products appraised in the CPGs and the developers of the guidelines. Conflict of interest forms were obtained from all authors and reviewed by an oversight committee prior to project initiation. AAN limits the participation of authors with substantial conflicts of interest. The AAN forbids commercial participation in, or funding of, guideline projects. Drafts of the guidelines have been reviewed by at least three AAN committees, a network of neurologists, Neurology ${ }^{\circledR}$ peer reviewers, and representatives from related fields. The AAN Guideline of Interest Policy can be viewed at www.aan.com.

Received September 25, 2009. Accepted in final form December 14, 2009

\section{REFERENCES}

1. EMD Serono, Inc. Novantrone (mitoxantrone) for injection concentrate [product monograph]. Available at: http://www. novantrone.com/assets/pdf/novantrone_prescribing_info. pdf. Accessed October 20, 2007.

2. Hartung H-P, Gonsette R, König N, et al. Mitoxantrone in progressive multiple sclerosis: a placebo-controlled, double-blind, randomized, multicentre trial. Lancet 2002 ; 360:2018-2025.

3. Goodin DS, Arnason BG, Coyle PK, et al. The use of mitoxantrone (Novantrone) for the treatment of multiple sclerosis: Report of the Therapeutics and Technology Assessment Subcommittee of the American Academy of Neurology. Neurology 2003;61:1332-1338.

4. Pratt RG, Boehm GA, Kortepeter CM, et al. Mitoxantrone treatment of multiple sclerosis: safety considerations. Neurology 2005;65:1997. Letter.

5. Krapf H, Morrissey SP, Zenker O, et al. Effect of mitoxantrone on MRI in progressive MS: results of the MIMS trial. Neurology 2005;65:690-695.

6. Vollmer T, Panitch H, Bar-Or A, et al. Glatiramer acetate after induction therapy with mitoxantrone in relapsing multiple sclerosis. Mult Scler 2008;14:663-670.

7. Ghalie RG, Edan G, Laurent M, et al. Cardiac adverse effects associated with mitoxantrone (Novantrone) therapy in patients with MS. Neurology 2002;59:909-913.

8. Edan G, Brochet B, Clanet M, et al. Safety profile of mitoxantrone in a cohort of 800 multiple sclerosis patients. Mult Scler 2001;7(suppl 1):S14. Abstract.

9. Mauch E, Eisenmann S, Hahn A, et al. Mitoxantrone (MITOX) in the treatment of patients with multiple scle- rosis (MS): a large single center experience. American Neurological Association; October 1999. Abstract.

10. Avasarala JR, Cross AH, Clifford DB, et al. Rapid onset mitoxantrone-induced cardiotoxicity in secondary progressive multiple sclerosis. Mult Scler 2003;9:59-62.

11. Paul F, Dörr J, Würfel J, et al. Early mitoxantrone-induced cardiotoxicity in secondary progressive multiple sclerosis. J Neurol Neurosurg Psychiatry 2007;78:198-200.

12. Goffete S, van Pesch V, Vanoverschelde JL, et al. Severe delayed heart failure in three multiple sclerosis patients previously treated with mitoxantrone. J Neurol 2005;252: 1217-1222.

13. Hamzehloo A, Etemadifar M. Mitoxantrone-induced cardiotoxicity in patients with multiple sclerosis. Arch Iranian Med 2006;9:111-114.

14. Khatri BO, Wroblewski M, Kramer J, et al. Mitoxantrone in worsening secondary progressive multiple sclerosis: a prospective, open-label study. Curr Ther Res 2006;67:55-65.

15. Ostberg A, Pittas F, Taylor B. Use of low-dose mitoxantrone to treat aggressive multiple sclerosis: a singlecentre open-label study using patient self-assessment and clinical measures of multiple sclerosis status. Int Med J 2005;35:382-387.

Kingwell E, Leung B, Isserow S, et al. Suspected cardiotoxicity during mitoxantrone treatment for multiple sclerosis British Columbia, Canada. Neurology 2009;72 suppl 3:A237-A238.

7. Hum S, Lapierre Y. A clinical retrospective report on mitoxantrone treatment in active multiple sclerosis patients. Neurology 2009;72 suppl 3:A237.

18. Zingler VC, Nabauer M, Jahn K, et al. Assessment of potential cardiotoxic side effects of mitoxantrone in patients with multiple sclerosis. Eur Neurol 2005;54:28-33.

19. Buttinelli C, Clemenzi A, Borriello G, et al. Mitoxantrone treatment in multiple sclerosis: a 5-year clinical and MRI follow-up. Eur J Neurol 2007;14:1281-1287.

20. Le Page E, Leray E, Taurin G, et al. Mitoxantrone as induction treatment in aggressive relapsing remitting multiple sclerosis: treatment response factors in a 5-year follow-up observational study of 100 patients. J Neurol Neurosurg Psychiatry 2008;79:52-56.

21. Rivera $\mathrm{V}, \mathrm{Al}-$ Sabbagh A, Bennett $\mathrm{R}$, et al. RENEW study update XVIII: Ongoing evaluation of the safety and tolerability of mitoxantrone in worsening multiple sclerosis. Mult Scler 2008;14 suppl 1:S175. Abstract.

22. Bernitsas E, Wei W, Mikol DD. Suppression of mitoxantrone cardiotoxicity in multiple sclerosis patients by dexrazoxane. Ann Neurol 2006;59:206-209.

23. Beaumont M, Sanz M, Carli PM, et al. Therapy-related acute promyelocytic leukemia. J Clin Oncol 2003;21: 2123-2137.

24. Felix CA. Secondary leukemias induced by topoisomerasetargeted drugs. Biochim Biophys Acta 1998;1400:233-255.

25. Vicari AM, Ciceri F, Folli F, et al. Acute promyelocytic leukemia following mitoxantrone as single agent for the treatment of multiple sclerosis. Leukemia 1998;12:441-442.

26. Ghalie RG, Mauch E, Edan G, et al. A study of therapyrelated leukemia after mitoxantrone therapy for multiple sclerosis. Mult Scler 2002;8:441-445.

27. Rammohan K, Kita M, Lynn DJ, et al. Post-marketing reports of acute leukemia in mitoxantrone-treated multiple sclerosis patients. Mult Scler 2008;14 suppl 1:S174. Abstract.

28. Pascual A, Boscá I, Mallacia J, et al. Secondary acute myeloid leukemia following long-term treatment with mitox- 
antrone in patients with multiple sclerosis. Mult Scler 2007;13:S23. Abstract.

29. Cordioli C, Cattaneo C, Capra R. Analysis of incidence, risk factors and prognosis of acute promyelocytic leukaemia related to mitoxantrone therapy in multiple sclerosis. Neurology 2007;68 suppl 1:A276. Abstract.

30. Woo DA, Collins RH, Rossman HS, et al. Mitoxantroneassociated leukemia in multiple sclerosis: case studies. Int J MS Care 2008;10:41-46.

31. Bosca I, Pascual AM, Casanova B, et al. Four new cases of therapy-related acute promyelocytic leukemia after mitoxantrone. Neurology 2008;71:457-458.

32. Debouverie M, Taillandier L, Pittion-Vouyovitch S, et al. Clinical follow-up of 304 patients with multiple sclerosis three years after mitoxantrone treatment. Mult Scler 2007; 13:626-631.

33. Tanasescu R, Debouverie M, Pittion S, et al. Acute myeloid leukaemia induced by mitoxantrone in a multiple sclerosis patient. J Neurol 2004;251:762-763.

34. Sadiq SA, Rammal M, Sara G. Chronic myeloid leukemia associated with mitoxantrone treatment in a patient with MS. Mult Scler 2008;14:272-273.
35. Martinelli V, Bellantonio P, Bergamaschi R, et al. Incidence of acute leukemia in multiple sclerosis patients treated with mitoxantrone: a multi-centre retrospective Italian Study. American Academy of Neurology annual meeting; Seattle, WA; 2009. Late-breaking abstract.

36. Brassat D, Recher C, Waubant E, et al. Therapy-related acute myeloblastic leukemia after mitoxantrone treatment in a patient with MS. Neurology 2002;59:954-955.

37. Goodkin DE. Therapy-related leukemia in mitoxantrone treated patients. Mult Scler 2003;9:426.

38. Cattaneo C, Almici C, Borlenghi E, et al. A case of acute promyelocytic leukaemia following mitoxantrone treatment of multiple sclerosis. Leukemia 2003;17:985986.

39. Heesen C, Bruegmann M, Gbdamosi J, et al. Therapyrelated acute myelogenous leukaemia (t-AML) in a patient with multiple sclerosis treated with mitoxantrone. Mult Scler 2003;9:213-214.

40. Delisse B, de Seze J, Mackowiak A, et al. Therapy related acute myeloblastic leukaemia after mitoxantrone treatment in a patient with multiple sclerosis. Mult Scler 2004;10:92.

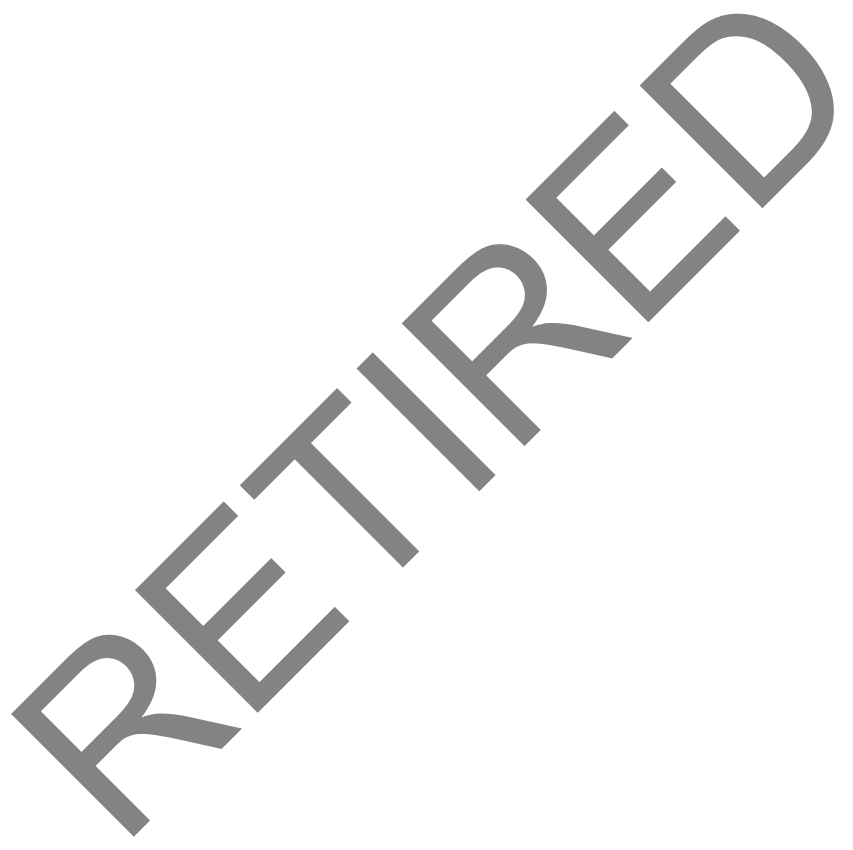




\section{Neurology}

Evidence Report: The efficacy and safety of mitoxantrone (Novantrone) in the treatment of multiple sclerosis [RETIRED]: Report of the Therapeutics and Technology Assessment Subcommittee of the American Academy of Neurology James J. Marriott, Janis M. Miyasaki, Gary Gronseth, et al. Neurology 2010;74;1463-1470

DOI 10.1212/WNL.0b013e3181dc1ae0

This information is current as of May 3, 2010

\section{Updated Information \&} Services

Supplementary Material

\section{Citations}

Subspecialty Collections

Permissions \& Licensing

\section{Reprints}

including high resolution figures, can be found at: http://n.neurology.org/content/74/18/1463.full

Supplementary material can be found at: http://n.neurology.org/content/supp1/2010/05/03/74.18.1463.DC1

This article has been cited by 10 HighWire-hosted articles: http://n.neurology.org/content/74/18/1463.full\#\#otherarticles

This article, along with others on similar topics, appears in the following collection(s):

Multiple sclerosis

http://n.neurology.org/cgi/collection/multiple_sclerosis

Information about reproducing this article in parts (figures,tables) or in its entirety can be found online at:

http://www.neurology.org/about/about_the_journal\#permissions

Information about ordering reprints can be found online: http://n.neurology.org/subscribers/advertise

Neurology ${ }^{\circledR}$ is the official journal of the American Academy of Neurology. Published continuously since 1951, it is now a weekly with 48 issues per year. Copyright . All rights reserved. Print ISSN: 0028-3878. Online ISSN: 1526-632X.

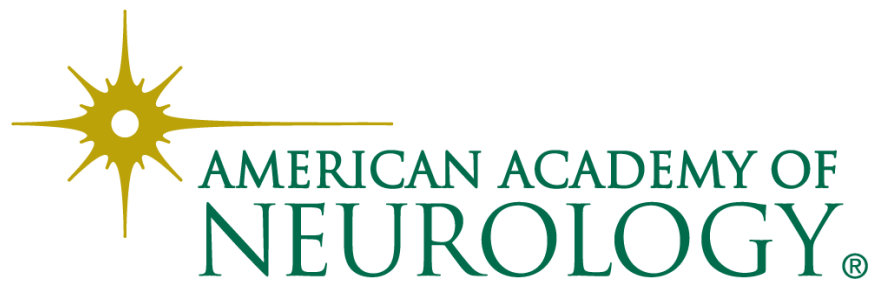

